For Emmanuel Levinas in homage 


\title{
PHENOMENOLOGICAL EXPLANATIONS
}

\author{
ALPHONSO LINGIS \\ (Pennsylvania State University)
}




\section{Distributors}

for the United States and Canada: Kluwer Academic Publishers, P.O. Box 358, Accord Station, Hingham, MA 02018-0358, USA

for the UK and Ireland: Kluwer Academic Publishers, MTP Press Limited, Falcon House, Queen Square, Lancaster LA1 1RN, UK

for all other countries: Kluwer Academic Publishers Group, Distribution Center, P.O. Box 322, 3300 AH Dordrecht, The Netherlands

\section{Library of Congress Cataloging in Publication Data}

ISBN-13: 978-90-247-3333-0

e-ISBN-13: 978-94-010-9610-2

DOI: $10.1007 / 978-94-010-9610-2$

\section{Copyright}

(C) 1986 by Martinus Nijhoff Publishers, Dordrecht.

Softcover reprint of the hardcover 1st edition 1986

All rights reserved. No part of this publication may be reproduced, stored in a retrieval system, or transmitted in any form or by any means, mechanical, photocopying, recording, or otherwise, without the prior written permission of the publishers,

Martinus Nijhoff Publishers, P.O. Box 163, 3300 AD Dordrecht, The Netherlands. 
PHENOMENOLOGICAL EXPLANATIONS 


\section{PHAENOMENOLOGICA}

COLLECTION FONDÉE PAR H.L. VAN BREDA ET PUBLIÉE

SOUS LE PATRONAGE DES CENTRES D'ARCHIVES-HUSSERL

96

ALPHONSO LINGIS

\section{PHENOMENOLOGICAL EXPLANATIONS}

Comité de rédaction de la collection:

Président: S. IJsseling (Leuven)

Membres: L. Landgrebe (Köln), W. Marx (Freiburg i. Br.), J.N. Mohanty (Oklahoma), P. Ricoeur (Paris), E. Ströker (Köln),

J. Taminiaux (Louvain-La-Neuve), Secrétaire: J. Taminiaux 


\section{CONTENTS}

$\begin{array}{lll}\text { Preface } & \text { IX }\end{array}$

I. On Phenomenological Explanation 1

II. The Mind's Body 21

III. Being in the Interrogative Mood 41

IV. Involution in the Sensuous $\quad 59$

V. The Perception of Others 73

VI. The Visible and the Vision 91

VII. Intuition of Freedom, Intuition of Law 103 


\section{PREFACE}

The intentional analysis devised by phenomenology was first used to explain the meaningfulness of expressions; it aimed at exhibiting the original primary substrates that expressions refer to, and at exhibiting the subjective acts that make signs expressive. The explanation of predicative expressions was then extended to the antecedent layer of prepredicative, perceptual experiences, explaining these by locating, with peculiar kinds of immanent intuitions, the original sensile data which evidence the bodily presence of the real - and by reactivating the informing formulating, interpreting - and the informing-forming subjective acts that make of the sensile data, or material, perceived things.

Intentional analysis explains by decomposing the derivate references back to the original references, and by leading the mind's intentions back to the givens they refer to. Can this kind of explanation be extended? The investigations of this book have taken this question in different directions. Can phenomenological explanation be extended to exhibit not only the act-character of the mind, but its substance, its affective materiality, its locomotion, its impressed haecceity, in short, its corporeality (Chapter I)? Shall not the explanation explain that if the terra firma of being, in the maximum proximity where distance no longer introduces indeterminability, is never reached, this is not because of the defects and the finitude of our mind, but because being itself is not there as the answer, positive and affirmative - being itself is in the interrogative mood (Chapter II)? If the given being itself is in the 
interrogative mood, then the sensile data or material that evidence its presence are not originally "sensations" - that is, impressions, on our sensory surfaces, of sense, signs or signals of identifiable identities. How can we formulate the format of that sensuous medium, and how explain that the sensibility by which our mind is exposed to the sensuous turns into a synoptic receptivity that posits data for the formation and interpretation performed by acts of perception (Chapter III)?

Phenomenological analysis explains, secondly, by exhibiting the subjective acts that originate the giving of the data, the objectification of the objects. This transcendental direction of the analysis aims to be an eidetic science - not only to formulate the actcharacter of one's own mind, but that of mind in general. How is the mind of another given - in what evidences, with what acts (Chapter V)? What does it mean to intuit intuition, to see a look (Chapter VI)? An imperative weighs on the mind from the first; to explain, as to think in general, is to find oneself subject to law, or, more exactly, to the imperative for laws, the imperative for the universal and the necessary. This law, said the transcendental philosophy of Kant, is a fact. Can this fact - the first fact, for facts can be recognized as facts by a mind that thinks, that is, formulates representations of the universal and the necessary - be given in an intuition? What is the original hyle in which this fact is impressed? What is the subjective act in which, and on which, this fact is given (Chapter VII)? 